\title{
Hernia de Morgagni
}

\section{Morgagni hernia}

Luis A. López Guzmán, Bettiana Torterolo, Juan C. Spina,Adriana García

Fronteras en Medicina 20 I8; I3(3): I76- 177. Doi: I0.3 |954/RFEM/20 I803/0 I76-0 I77

La hernia de Morgagni (HM) es la forma más frecuente de hernia retroesternal que se produce a través del triángulo esternocostal (foramen de Morgagni o triángulo de Larrey). La misma se encuentra adyacente al apéndice xifoides del esternón, siendo el lado derecho el más afectado. Se produce por un defecto en la fusión del tabique transverso a la pared lateral del cuerpo, a lo que se añaden factores ambientales como la presión abdominal, degeneración diafragmática, obesidad, etc ${ }^{1}$. Representan un 9-12\% de las hernias diafragmáticas congénitas y son más frecuentes en el lado derecho (90\%), ya que el saco pericárdico protege el lado izquierdo. Habitualmente tienen un saco herniario íntegro, bien definido y se diagnostican de manera incidental en niños mayores y adultos, siendo de curso asintomático ${ }^{2}$. Por el contrario, las diagnosticadas en período neonatal son habitualmente sintomáticas (distrés respiratorio, infección

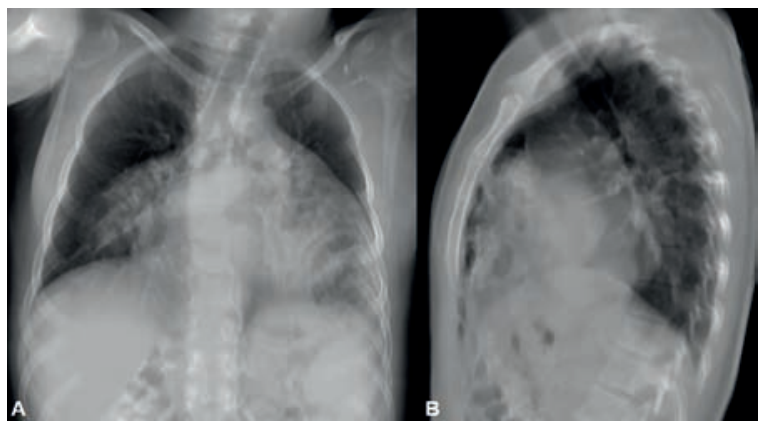

Figura I. Radiografia de tórax frente (A) y perfil (B) en las cuales se observa, a través de la silueta cardíaca y la región basal paracardíaca derecha, la presencia de múltiples imágenes radiolúcidas sugestivas de asas intestinales.

Servicio de Diagnóstico por Imágenes, Hospital Británico de Buenos Aires, CABA

Correspondencia: Dr. Luis A. López Guzmán. Servicio de de Diagnóstico por Imágenes, Hospital Británico. Perdriel 74, CI280AEB CABA, Rep.Argentina. Tel 54II 43096400 int 2753. Email: allopez@hbritanico.com.ar

Los autores declaran no tener conflictos de intereses. respiratoria o sintomatología gastrointestinal inespecífica) y se presentan habitualmente asociadas a otras anomalías congénitas, como la trisomía del cromosoma 21 (14\%) y las cardiopatías congénitas $(58 \%)^{2}$.

Pueden observarse asas intestinales en mediastino anterior en la radiografía de tórax o bien en otras técnicas (tomografía computarizada [TC] o resonancia magnética $[\mathrm{RM}])$. Habitualmente se visualiza una masa sólida o con gas en el ángulo cardiofrénico ${ }^{3}$. La ecografía y la TC (eventualmente RM) demuestran con mayor precisión el contenido de la hernia.

Dado el riesgo asociado de obstrucción intestinal con incarceración y estrangulación, deben ser reparadas quirúrgicamente independientemente de la presencia de síntomas. La corrección se realiza habitualmente mediante cierre primario y la mayoría de los casos se pueden resolver con abordaje laparoscópico².

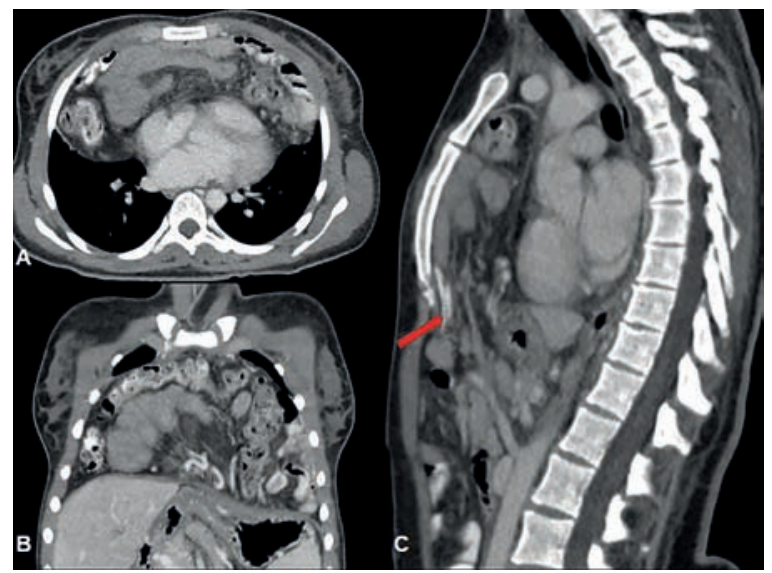

Figura 2. TC de tórax con contraste EV. Corte horizontal (A), coronal (B) y sagital (C). Se evidencia la magnitud y contenido de la hernia referida, ocupando gran parte de la cavidad torácica. Se destaca la topografia del triángulo esternocostal (flecha roja en imagen C) como sitio de transición entre las cavidades abdominal y torácica. 


\section{BIBLIOGRAFÍA}

I. I. Nason LK, Walker CM, McNeeley MF, Burivong W, Fligner CL, Godwin JD. Imaging of the Diaphragm: Anatomy and Function. RadioGraphics 20 12;32:E5 I-70.

2. 2.Ayala Calvo G, Coca Robinot D, Mandich Crovetto D, Rico Aragón E, Guerrero Salcedo N, Gallego Herrero C. Hernias diafrag- máticas congénitas: Hallazgos radiológicos postnatales. Radiología 20| 4;56: 1227.

3. 3. Del Cura JL, Pedraza S, Gayete A. Radiología esencial. Editorial Médica Panamericana; 2015;89-291. 